\title{
Comparative perspectives: regulating insurer use of genetic information
}

\author{
Anya E.R. Prince ${ }^{1}$
}

Received: 29 August 2018 / Revised: 3 October 2018 / Accepted: 16 October 2018 / Published online: 6 November 2018

(c) European Society of Human Genetics 2018

\begin{abstract}
Fear of genetic discrimination has led individuals worldwide to avoid medically recommended genetic testing and participation in genomics research, causing potential health effects as research and clinical care are stymied. In response, many countries have adopted policies that regulate how insurers, such as life, disability, or critical illness insurers, can underwrite using genetic test results. This article presents a comparison of policies in the United Kingdom, Canada, and Australia, through analysis of interviews with 59 key stakeholders representing insurance, government, advocacy, academia, and genetics. While the ultimate policy of each country is different, the policy motivations and issues raised share commonalities across the countries, particularly around themes of fairness, usefulness of genetic information, and the determination of actuarial fairness.
\end{abstract}

\section{Introduction}

Societies across the globe have debated whether it should be legal for insurers to consider the genetic information of applicants. Insurers argue access to genetic test results is a necessity to properly classify risk and assess premiums. Individuals, however, feel this would amount to genetic discrimination. Fear of genetic discrimination has led individuals to avoid genetic testing in clinical care and research, leading to potential negative health consequences as research and individual care is interrupted [1]. Countries have adopted various regulatory mechanisms to address insurer use of genetic information in private, individually underwritten insurances, like life, critical illness, long-term care, and income protection [2-6]. These regulatory solutions range from legislative bans on use, to moratoria, to restrictions on when insurers can use the information, to industry self-guidance [2].

This comparative case study analyzes policies regarding insurer use of genetic information in three countries: Australia, Canada, and the United Kingdom (UK). The

Anya E.R. Prince

anya-prince@uiowa.edu

1 The University of Iowa College of Law, 130 Byington Road, \#280 BLB, Iowa City, IA 52242, USA countries were chosen to represent different policy approaches-respectively, guidance, legislation, and moratorium. The analysis focuses on private, individually underwritten insurances, but does not include health insurance since the health care systems of these countries are national. The article reports findings from interviews with key stakeholders regarding each policy, its reasoning, and consequences. Overall, common themes around fairness and actuarial determinations arose, despite the ultimate differences in policy options.

\section{Materials and methods}

Between May 2016 and March 2017, I conducted semi-structured interviews with key stakeholders representing government, advocacy, insurance, academia, and the medical genetics communities. Although some interviewees fell under two or more stakeholder categories, participant classifications reflect the interviewee's predominant perspective on the issue. There were 19 stakeholder interviews from Canada, 22 from the UK, and 18 from Australia (Table 1). The University of North Carolina (UNC) Institutional Review Board approved this research. Local ethics experts were also consulted in each country and additional review was not recommended given the subject matter of interview questions. 
Table 1 Interview participants

\begin{tabular}{lllllll}
\hline Country & $\begin{array}{l}\text { No. of } \\
\text { Academia }\end{array}$ & $\begin{array}{l}\text { No. of } \\
\text { Government }\end{array}$ & $\begin{array}{l}\text { No. of } \\
\text { Genetics }\end{array}$ & $\begin{array}{l}\text { No. of } \\
\text { Insurance }\end{array}$ & $\begin{array}{l}\text { No. of } \\
\text { Advocacy }\end{array}$ & $\begin{array}{l}\text { No. of } \\
\text { Total }\end{array}$ \\
\hline Canada & 6 & 4 & 3 & 4 & 2 & 19 \\
United & 10 & 1 & 3 & 5 & 3 & 22 \\
Kingdom & & 3 & 4 & 3 & 3 & 18 \\
Australia & 5 & 8 & 10 & 12 & 8 & 59 \\
Total & 21 & & & & & \\
\hline
\end{tabular}

\section{Results}

\section{United Kingdom}

In 2001, the UK insurance industry voluntarily agreed to a moratorium on underwriting based on predictive genetic test results. Under this moratorium, insurers cannot consider predictive genetic test results for life, critical illness, and income protection policies under a set monetary cap [7]. The moratorium was replaced in October 2018 by a voluntary code of practice developed by the government and the ABI, but the structure of the agreement remains similar [8]. For policies over the amount, such as life insurance policies over $£ 500,000$, insurers only consider those predictive genetic tests approved by an independent panel. Since implementing this two-tiered system, only Huntington's Disease for life insurance has been approved.

The moratorium has been renewed continuously since implementation and it is generally believed that it will continue for the foreseeable future. As one UK academic stated, "I don't think anyone is going to have to go into legislation... I would be amazed if it wasn't quietly extended again and again and again." This response was echoed among the insurance industry: "I think the broad principles of it will, and probably should, continue." While some interviewees were initially skeptical about the temporary solution, its continued renewal has tempered their concerns. As one academic said, "[T]here was very little change between 1999 and 2001, and it's been completely unchanged [since then]. And so what's that? Fifteen years, and there's no prospect really of it ever being removed. I think it has put the issue to bed." Although stakeholders felt continued renewal was likely, interviewees often spoke of a future where increasing knowledge of genetics might force changes to the moratorium.

Although individuals across all groups of stakeholders felt the moratorium was effective, a couple areas of concern were raised during interviews. For example, four stakeholders brought up the issue that travel insurance is not covered by the moratorium, and therefore is an area where there are lingering concerns regarding genetic discrimination. Additionally, the UK interviews were conducted in the week immediately prior to and immediately after the Brexit vote. Several stakeholders discussed new uncertainty as to how the political upheaval of the UK leaving the European Union might affect existing policies. One academic interviewee felt that the moratorium works well in part because of a background threat of legislation if the industry ever opts out of the moratorium. When asked whether she believed that the legislature would act if the moratorium ever fell apart, she said, "[b]efore Thursday I would have said 'Yeah. Of course.' Now I can't. Who knows what Parliament is actually going to be able to do over the next few years."

\section{Canada}

In Canada, the landscape regarding permissible insurer use of genetic information has recently undergone major change. In March 2016, when interviews were conducted, life and other private insurers of individual policies could consider genetic testing. However, Parliament was debating the Genetic Non-discrimination Act (GNA), which ultimately passed in March 2017. The GNA prohibits use of genetic test results in the formation of contracts, including insurance contracts [9].

The interviewees favoring the bill argued that it would alleviate fears of genetic discrimination, increase the uptake of testing, and fill legislative gaps since Canada was, as a government stakeholder noted, "the only leading country in the world that [didn't] have any protection at either the federal or provincial level." The insurance industry opposed on multiple grounds. It was most worried with the imposition of information asymmetry between applicants and companies. An industry stakeholder noted, "really we're concerned about [the section] which says, "even if you have relevant information, you don't have to tell the insurer.", Insurers also argued that the federal legislation was unconstitutional because insurance is generally the purview of the provinces. Given constitutional concerns, the legislation is undergoing judicial review.

Additionally, due to the federalist system in Canada, there is some question regarding the overall impact of the bill, including provisions related to employment. An academic argued, "I think the bill has no substance. I mean no, it has substance, but its application from a legal standpoint is going to be really a narrow category of people for a very narrow category of cases... so basically, it's something that 
Table 2 Heat of the debate: United Kingdom and Canada

\begin{tabular}{|c|c|c|}
\hline Country & Quote & Stakeholder Group \\
\hline UK & $\begin{array}{l}\text { Back in the 1990s... the Association of British Insurers (ABI) swung from being very aggressively pro genetic- } \\
\text { the right to underwrite- to compliance with the moratorium. I think that's what the Canadians failed to do. } \\
\text { They're still in the spirit of the original ABI's tack of having the right to underwrite, or otherwise there will be a } \\
\text { disaster. }\end{array}$ & Insurance \\
\hline UK & $\begin{array}{l}\text { As I say about fifteen, twenty years ago it became one of those issues that the press likes to seize on because you } \\
\text { know it's got all the elements of a good story. You've got families with a life limiting condition which is } \\
\text { incurable. You've got doctors who are telling them that they need to be responsible and make arrangements and } \\
\text { what have you, and you've got these evil companies who are willfully denying them the opportunity because of } \\
\text { something which is not their fault. So, it all bubbled up, and as a result there were demands for legislation. The } \\
\text { industry was saying 'You know if we can't use genetic information, then you know all sorts of dire consequences } \\
\text { will follow, and we'll all go to the wall, and it will be awful, and you know there will be weeping and wailing and } \\
\text { gnashing of teeth, and we'll take our ball home.' And you know all this sort of knee jerk reaction. }\end{array}$ & Advocacy \\
\hline UK & $\begin{array}{l}\text { I'm aware of the debate [in Canada] which looked terrible to me. There was an enormous amount of sort of fuss } \\
\text { and discussion, and it was discussion which I felt was crazy that it had to be had. }\end{array}$ & Insurance \\
\hline UK & $\begin{array}{l}\text { At the time [the moratorium] came in there was an awful lot of heated discussion and lots of very unfair and } \\
\text { incorrect press coverage. There was loads of fair and mis-reporting, and the introduction of the moratorium very } \\
\text { soon did quiet that down. Everything has gotten a lot quieter, it's been a lot more controlled, and that hot debate } \\
\text { and reputational damage has gone away. }\end{array}$ & Insurance \\
\hline
\end{tabular}

you do more in the hope to influence other people and hope to reassure people." Another academic noted that "it may inspire the provincial human rights commissions or the provincial governments to enact similar provisions."

One of the most notable differences across countries, especially between Canada and the UK, was the intensity of the debate. The language used by some Canadian stakeholders was more emotional and antagonistic than in the other countries. Interviewees described those involved in the debate as "purposely misleading" or "wrong-headed." In response to arguments raised, they stated "that pisses me off actually" and "I don't even know how they can keep a straight face when they present that because it was so biased." This heightened language came from stakeholders across groups, including insurers, academics, and government. Yet, the heightened antagonistic positioning was not present in the UK and Australian interviewees, perhaps because the Canadians were in the middle of major policy debate when the interviews occurred. Interestingly, several UK interviewees reflected on how Canada reminded them of the early debates in the UK pre-moratorium. They agreed that originally there was the heightened debate and bluster stemming from discrimination and economic concerns, but that the moratorium "took the heat out of the debate." (Table 2).

\section{Australia}

In contrast to the UK and Canada, Australia does not have a moratorium or legislation directly regulating insurer use of genetic information. Australian anti-discrimination law allows insurers to use medical information, including genetic information, as long as decisions are "based upon actuarial or statistical data on which it is reasonable...to rely." [10] In 2003, an extensive report, titled Essentially Yours, was published on the implications of genetic testing across society [10]. While it found that the general principles related to risk classification and duty to inform in applications should remain, it recommended expert review regarding which genetic results should be used by insurers [10]. However, these particular recommendations were never implemented, leaving the industry as the ultimate adjudicator.

This system has been critiqued as giving insurers too much freedom without sufficient government oversight. As an Australian academic pointed out, "I still have concerns that even though technically we have a protection through the Disability Discrimination Act (DDA) legislation, that the onus is too much on the individual to fight for their rights." Another academic voiced similar concerns, "Essentially Yours... made many recommendations around what should be happening in this space, and I guess our feeling is that those things haven't been done. So, it's really been just left to chance as to how insurers use it and how individuals understand it. I would see it as fairly unregulated."

On the other hand, others argued that Australian insurers have generally been using genetic information responsibly. An academic noted, "There certainly are a few cases, but I don't think there is widespread systemic discrimination practiced." This belief is supported by independent empirical research $[11,12]$. This research results from an unintended benefit produced when insurers can access genetic information-by allowing access to genetic test results, Australia has accumulated a wealth of data regarding insurer use of genetic data. An Australian reinsurer highlighted the benefits of collected data. In response to a question about how insurers take into account the low 
penetrance and preventive options associated with hemochromatosis, he answered,

I can confidently answer that by stating that insurers will be, and need to be, well aware and attuned to all such aspects of medical conditions. I think that is one of the big advantages we have had of collecting data here. I could probably say to you that our data support that statement that I've just made in that the vast majority of people that are hemochromatosis positive genetically are accepted at standard rates for life insurance.

\section{Interview themes}

Despite the differences in country policies, stakeholders raised several common themes surrounding discussions of fairness and actuarial standards. There were often more similarities across the countries, following similar trends across stakeholder groups in each country. Three common themes were raised in each country: fairness, usefulness of genetic information, and who should determine actuarial relevance.

\section{Fairness}

Interviewees across countries and stakeholder groups often framed the debate as a question of fairness. In all, over a third of respondents used the terms "fair" or "fairness" during discussion, although others used comparable terms. However, there were different groups that the interviewees were worried about being "unfair" to: individuals with genetic conditions, insurers, and the broader society. Not surprisingly, insurers were more likely to raise industry fairness concerns and the other stakeholders were more likely to raise concerns of individual fairness. However, many interviewees raised multiple conceptualizations of fairness and acknowledged the difficulty of creating policy that balances all fairness concerns.

Fairness to individuals with genetic predispositions If insurers can underwrite on the basis of genetic information, some may be unable to access insurance or be charged higher premiums. Two individuals in the Canadian medical genetics community felt strongly about this issue. One said, "I come at this as a care provider for people that have very high risks, and I feel it's fundamentally unfair for them to be denied insurance or to have to pay extremely high premiums because they're in a small high-risk group." The other expressed a similar stance, "to me a good subset of our patients was not the luckiest in the genetic lottery, and that shouldn't be a reason to penalize them a second time around."

Others acknowledged that what may seem unfair to an applicant may not rise to the level of being unlawful. Insurance may not be completely 'fair' for everyone involved, but this is a natural aspect of commercial markets. As an Australian academic framed it, "What people might think is unfair versus what is actually unlawful, are often different. People may have the perception that they have been somehow stigmatized or discriminated against, but that's a much larger group than those where the law would actually establish that it was not warranted." A UK academic echoed this view, "So I suppose [the premiums for people with genetic predispositions] might be a little bit more expensive, but then you answer 'Well, is it unjust or just unfair?"'

Fairness to broader society While fairness to individuals with genetic conditions was a common theme, many interviewees, predominately in the UK and Canada, also noted that altering policy to address this could have broader consequences. A UK advocate described an aspect of the problem if insurers cannot use genetic information:

[Insurers] will adjust their premiums accordingly, and it won't be in a downward direction. So, in a sense, addressing unfair genetic discrimination may make it more difficult for families at risk of genetic disorders to purchase insurance because it's moved out of their affordability bracket. That may affect far more people than those just at risk of a genetic condition.

This argument was raised most often by Canadian insurers, perhaps because it was a strategic line of argument against the GNA and because commissioned studies estimated increased premiums if the bill passed [13]. Several Canadian insurers also noted that this increased cost would be borne only by that portion of society purchasing insurance. As one stated, "Premiums are going to increase, but it's only going to increase among people who take out insurance. Why is it? Why is it that people who don't need, don't want, don't care, whatever for insurance are let off scott free?"

Another formation of this fairness argument was that it is unfair to treat those with genetic conditions differently than individuals with non-heritable diseases. A Canadian academic described this problem: "Again, there I think it shows you the difficulty of focusing more narrowly on genetics because there's... potential unfairness that is much broader than genetic unfairness." 
Fairness to insurers Regulating insurer use of genetic tests has potential for far-reaching consequences for the insurance industry at large. This was commonly raised by insurers, although members of the advocacy and academic groups also acknowledged that some policies may not be fair to the insurers themselves. "I think it's important that there's some - that the industry is respected. We can't have it be unfair to them as well." An Australian advocate highlighted why a ban may be unfair to insurers: "I mean, to say ban it altogether, that's not fair because then you will have those people who maybe try to rob the system [through anti-selection]." Other academics and advocates however, did not express as much concern for the industry's position. As a UK advocate summarized, "I mean who knows really? Last time I looked it was still by and large occupying marbled halls with vast atria and running water and palm trees in the lobby. So I don't think the industry is on its uppers as a result of a sustained campaign of anti-selection by evil patients with mutations."

\section{Actuarial relevance}

A member of the genetics community in Australia summarized why the concept of fairness is so integral to discussion of insurance underwriting, "I think the big issue is not discrimination, because discrimination is the watch word of insurance. I mean, that's what they do... It's unfair discrimination, and that's the issue." This is a common theme, not just for the interviews, but also for insurance literature. For an insurer to use a risk characteristic in underwriting, it should be actuarially relevant-that is, there should be a correlation between the risk factor and cost to the insurer. If an insurer employs a risk factor without actuarial relevance, this would be unfair discrimination. Despite the common usage, the term "actuarial relevance" (sometimes described as "actuarial justification") is not precisely defined. As a UK academic explained, "I tried to find out what actuarial relevance actually meant within the industry. The closest I could find to a definition... was that which an actuary thinks is relevant." A UK respondent from the insurance field shared a nuanced assessment of actuarial relevance, differentiating between individual and societal levels,

[The] requirement that insurers must show a statistical correlation between a risk factor and increased cost in order to use that factor is what is usually regarded as the actuarial justification for using genetic information. I would argue there's a second area of actuarial justification. The second area is if we use genetic information... how much difference does it make to the system as a whole? How much difference does it make to the overall finances?
While the other respondents did not use this specific language, both conceptions of actuarial justification arose.

Actuarial relevance at the individual level Many interview subjects raised questions about how useful genetic test results were to determining individual risk, and thus estimated cost to insurers. While they acknowledged that some genetic tests were helpful at determining risk for future disease, they noted that the vast majority of genetic tests are not that good at accurately predicting risk at this time. For example, a Canadian academic argued, "unless it's one of those rare Mendelian disorders where you know that you've got a seventy to ninety percent probability of getting breast or colon cancer, I'm not sure how useful that information is." Other examples of quotes along this theme are highlighted in Table 3. Interviewees across countries and stakeholder groups including, notably, insurers raised the theme of usefulness.

There were others who assumed that genetic test results would have actuarial relevance. For example, an academic worried about the discriminatory effects of insurer use of genetic information noted, "I think there probably is an actuarial justification for using genetic information. But I still think it's wrong to do so."

Despite the fact that respondents from all stakeholder groups generally acknowledged the lack of robust risk information for most genetic tests, many noted that this might change in the future as scientific understanding develops. An academic in Canada speculated, "I think [insurers] are actually much less interested in genetic information than we think they are. I think that they just find it's complicated and expensive. I think they just want to keep their right to access information." Another UK academic noted how big data and technology could help insurers use genetic test results with smaller effect sizes, "so I believe that the scale of different datasets here and our ability to integrate them will feed back on how well we can understand genetic sequences... not necessarily the causative mechanisms, but how we understand them in terms of robust associations that then become for insurance companies actionable because insurance companies don't care about the causative mechanisms."

The uncertainty of rapidly emerging science was one reason that the UK moratorium was adopted-to add flexibility into the system to accommodate the discovery of new, relevant genetic tests. However, as one academic noted, this has not come to fruition, "It seemed to me at the time there was an uncertainty as to just how useful this information would be. And I think I might have expected the uncertainty to have been addressed more fully than it seems to have been at this point." Another respondent from UK insurance questioned whether future updates will ever change the industry, "I don't anticipate there are going to be hundreds of tests that are like Huntington's Disease." A 
Table 3 Usefulness of genetic test results for insurers-individual level

\begin{tabular}{|c|c|c|}
\hline Country & Quote & Stakeholde \\
\hline $\mathrm{AU}$ & $\begin{array}{l}\text { For the most part, we just don't have data where we understand the penetrance and risk, supported by population } \\
\text { data. It's just not there in most cases. }\end{array}$ & Genetics \\
\hline $\mathrm{AU}$ & $\begin{array}{l}\text { But I do think [genetic test results are] relevant information... The evidence doesn't suggest that it should be } \\
\text { given any special weighting, just appropriate weighting... It's probably misunderstood in the community. And so } \\
\text { perhaps is given a greater significance and perhaps that misunderstanding is then adopted by insurers or policy } \\
\text { makers. }\end{array}$ & Advocacy \\
\hline UK & $\begin{array}{l}\text { Yes, if you're homozygous for the ApoE4 mutation, then you have, I think, a } 15 \% \text { greater chance than the } \\
\text { population of developing Alzheimer's disease by the time you are eighty. Well, that's nasty, but to an insurer } \\
\text { that's negligible because you're thirty now, and you know you're looking for a thirty-year policy to cover your } \\
\text { mortgage. So, you'll keep paying... }\end{array}$ & Advocacy \\
\hline $\mathrm{CA}$ & $\begin{array}{l}\text { Genetic testing is not anywhere near as accurate as people paint it to be with the exception of approximately } \\
\text { twelve monogenic diseases... I mean no company wants to waste their money by asking for tests that don't } \\
\text { provide some kind of value... It's such a poor prognosticator of whether somebody's going to develop a disease } \\
\text { or not that right now it just doesn't work as well as the more commonly used tests, whether it's urine test or blood } \\
\text { test and so forth. }\end{array}$ & Insurance \\
\hline $\mathrm{CA}$ & $\begin{array}{l}\text { If you just talk about } 23 \text { andMe... you almost say, 'Well, you know what? Probably } 99.9 \% \text { percent. (I'm making } \\
\text { that number up). It's probably quite irrelevant. Thank you very much.' At least now. Right. Ten years from } \\
\text { now.... }\end{array}$ & Insurance \\
\hline
\end{tabular}

Canadian insurer acknowledged this, but noted that the way that insurers use the genetic tests with smaller effect sizes may change, "insurers are not going to get too much bang for their buck after the impacts of the top twenty or so genetic tests are analyzed today. However, I see the future for life insurance similar to the car insurance industry, where the winners are the companies that have the most data on the individuals - they can refine the price the best."

Actuarial relevance at the system level In addition to discussions of how genetic information helps, or does not help, to predict individual risk, interviewees also discussed whether the inability to use genetic test results would affect the insurance industry and premium rates at large - the second conception of actuarial justification discussed above. Here too, respondents questioned how much of a change there really would be. "The extra information that we get from [genetic tests] over knowing how old your parents were when they died... is so minimal that it wouldn't be a benefit. So, in life insurance, it probably doesn't really matter. There's no strong reason to prohibit it, but I don't think there are very strong reasons either to allow it." These themes appeared less often than the first conception of actuarial relevance, but were discussed by some interviewees (Table 4). Notably, this theme appeared most often in the UK. There are several, likely related, reasons why this might be true. First, the independent review body that was established in the UK adopted standards requiring insurers to show actuarial relevance at the system level, so this concept is perhaps more commonly understood across the country. Second, one of the leading actuaries who models the impact of genetic test results on insurance is in the UK and his work may be more commonly known by stakeholders in the country [14].

\section{Who should determine actuarial relevance?}

Stakeholders from both insurance and other groups noted this lack of broad utility for many genetic tests. As a Canadian insurer described, "If it ain't scientifically valid (if you'll pardon my English) you ain't gonna use it because that would not be appropriate. So in order to use it you better darn make sure that the test has the degree of validity that is necessary to give it the weight that you are giving in your assessment." This highlights a second, more policyoriented theme regarding who should determine the actuarial relevance of the tests. Some, like the insurer above, made clear that the insurance industry is capable of conducting this assessment. Others, argued that insurers do not have the expertise. An Australian academic argued, "Actually determining whether an individual variant warrants disclosure is proving incredibly difficult, which says something about the likelihood of an insurance company being able to interpret that kind of information in a way that can legitimately feed into an insurance premium." After discussing the complexities of determining the penetrance and prevelance of genetic conditions, an Australia geneticist quipped, "we don't know as health professionals who spend our lives thinking about very little else, then how on earth are the actuaries going to give you a good principle?"

The debate about greater oversight was most prevalent in Australia, likely because the UK moratorium already provides an independent review and Canada was debating the complete ban. Several interviewees in Australia felt that some independent review or other transparent process was necessary. An Australian advocate summarized this concern, "I guess there needs to be a whole system of checks 
Table 4 Usefulness of genetic test results for insurers-system level

\begin{tabular}{|c|c|c|}
\hline Country & Quote & Stakeholder Group \\
\hline $\mathrm{CA}$ & $\begin{array}{l}\text { So, for example, if it would appear that only about three percent of the population would hold important genetic } \\
\text { information relating to mortality risk, then probably that's a number that's small enough that the insurance } \\
\text { companies-they all agreed to just ignore that information and let people buy as much life insurance as they want } \\
\text { at the same price as everyone else. }\end{array}$ & Academic \\
\hline UK & $\begin{array}{l}\text { Then the insurance industry realized that actually not all genetics was like Huntington's disease... Most people } \\
\text { still live to be about eighty, and most people die of dementia, skeletal failure, heart failure, or cancer, and although } \\
\text { these have a genetic element they're not genetic diseases in the Mendelian sense and, anyway, if you've had } \\
\text { somebody paying insurers until they're eighty, you probably got a fair whack out of them. }\end{array}$ & Advocacy \\
\hline UK & $\begin{array}{l}\text { There's a common misperception outside the insurance industry that very, really quite small shifts in risk are of } \\
\text { tremendous importance to insurance, and they're not. }\end{array}$ & Insurance \\
\hline UK & $\begin{array}{l}\text { At the moment I don't think [genetic test results are] terrifically useful. I mean we're looking here at the added } \\
\text { value over and above the information insurers already have, [such as] where you require disclosure of a person's } \\
\text { medical history... at the moment it doesn't have that degree of added value. I wouldn't discount the possibility } \\
\text { that we're coming to a period where there is significant added value, that we understand so much more about the } \\
\text { genome that we can be more confident that you have added risk there. }\end{array}$ & Academia \\
\hline UK & $\begin{array}{l}\text { I know the researchers hope it will change, but the DNA information for the common complex diseases doesn't } \\
\text { add much to current risk stratification models. }\end{array}$ & Genetics \\
\hline UK & $\begin{array}{l}\text { So quite a few of these people would tend to have a family history, and the family history may mean they'd } \\
\text { already be rated or possibly declined anyway. So, it's the difference between a family history rating and an } \\
\text { adverse test rating. So, it's quite a confined, limited problem." }\end{array}$ & Insurance \\
\hline $\mathrm{AU}$ & $\begin{array}{l}\text { Here the legislation says, 'Well, in the absence of reasonable actuarial data, you can rely on anything else which is } \\
\text { reasonable effectively.' And I-I think if it came down to it, most insurers would admit that they're relying on } \\
\text { that." }\end{array}$ & Insurance \\
\hline
\end{tabular}

and balances that need to be put in place to ensure that insurers are actually using that information properly."

Although Australian academics and geneticists were more likely to raise questions regarding the ability of insurers to properly assess genetic data, some interviewees acknowledged the nuance between the difficulty of assessing risk and insurers' reasonableness in accessing the information. For example, an Australian academic noted, "We're constantly updating our models... trying to get them more and more accurate, and yet I don't know what insurance companies are doing. Are they using our models? But, I guess at the point that you're giving it to patients, you must be confident enough to know what it means, and therefore I guess then the insurance company should be able to use it if it's something that patients are being told about." Unsurprisingly, it was the insurers who most often raised the argument that they undertake risk assessment all the time and should be trusted in that endeavor, although this was supported by stakeholders from academia and government as well.

\section{Discussion}

Stakeholder groups across all three countries-the UK, Canada, and Australia-discussed common themes surrounding whether private, individually underwritten insurance policies should be able to underwrite on the basis of genetic test results. Three common themes arose regarding questions of fairness, the usefulness of genetic information, and who should determine the actuarial relevance of the information.

Discussions of fairness were a common themes discussed across stakeholders and countries. However, the interviews highlighted different concepts of fairness that are often in tension. Insurer access to genetic test results may be unfair to individuals with genetic predispositions, however, restricting insurer use may be unfair to insurers or the broader society. Many stakeholders raised multiple aspects of fairness, showing why this is such a difficult debate-if a policy is fair to one segment of society, it may unfairly affect another segment, whether intentionally or unintentionally.

A ban or restriction on insurer use of genetic information would be more "fair" to those with genetic predispositions, but could economically hinder the insurance industry and therefore raise premiums for the broader insured community. The economic impact of this, however, is dependent on how useful genetic information is to insurance calculations. Many stakeholders across all countries, including those from insurance, questioned whether genetic information was useful at both the individual and societal level. Currently, many genetic test results do not accurately predict risk sufficient for use by insurers or indicate very small increased risk. However, if technology advances lead to more accurate risk prediction-for example through a better understanding of gene/environment interactions-the 
economic impact of an inability to use genetic information could increase. Insurers are interested in maintaining their ability to use genetic information, perhaps less for how they will use it currently, but to maintain the ability to assess and use in the future. Therefore, a long-term and inflexible policy is worrisome to them.

The growing landscape of genomic testing will also increase economic pressures on insurance companies in two primary ways. First, as more asymptomatic individuals opt for genomic testing in order to prevent future disease as part of wellness or public health efforts, there will be an increasing number of at-risk individuals identified who do not have family history or symptoms of disease. Second, as more individuals receive genomic screening within a diagnostic setting, they may receive results of incidental findings for genetic predispositions for which they are currently asymptomatic. These scenarios are especially worrisome for insurers since this situation increases the risk of asymmetrical information about genetic risk between insurers and applicants, and thus increases the potential economic impact of a possible ban on use of genetic information.

Despite the common themes across countries, there were some notable differences. In the UK, travel insurance was raised as an area of concern. Since the moratorium was seen as an effective way to assuage fear of genetic discrimination in life, critical illness, and income protection insurance, concern over possible gaps has moved to travel insurance. In Canada and Australia, stakeholders remain focused on personal lines of insurance closely associated with medical underwriting likely because a comprehensive policy solution for these concerns had not yet been established.

In Australia, interviewees were most likely to raise themes regarding whether insurers could be trusted to accurately assess the actuarial relevance of genetic information. This is perhaps because Australia currently relies on industry self-regulation, so the effectiveness of the policy rests on the accurate assessment of the industry, without any government oversight. To a lesser extent, Canadian insurers also raised this theme by arguing that they could be trusted to use genetic data appropriately, because they were arguing to maintain the status quo in Canada of insurance selfregulation rather than passage of the GNA. This aspect of the debate was not raised in the UK, where independent oversight of actuarial relevance is a long-established norm.

As discussed, the most notable difference in Canada was the emotion of the debate compared to Australia and the UK. However, despite the best efforts of the insurance industry, the Canadian Parliament passed a strict ban on insurer use of genetic information. The ultimate impact of this bill remains to be seen, as it is undergoing constitutional review.
Given the common and specific themes raised during the interviews, it is understandable why the UK is often highlighted as a model policy option. The difficulty of creating policy in this area is that there are competing concerns of fairness and the impact of a policy depends on the usefulness of genetic information to insurance underwriting. There are also questions of trust as to who should assess the actuarial relevance of genetic information. The UK moratorium balances between all three of these themes. First, the monetary cap ensures at least some access to insurance for those with genetic predispositions, while simultaneously limiting the economic impact of the restriction. Second, there is independent review to systematically monitor the usefulness of genetic information with input and assessment by both the insurance industry and government appointed reviewers. Finally, the temporary nature of the agreement provides flexibility and the opportunity for reassessment if the usefulness of genetic information for determining risk changes greatly in the future. Countries considering regulating insurer use of genetic information should assess how well their proposed system meets these three concernscompeting views of fairness, assessment of the usefulness of genetic information, and flexibility to adapt to the changing understanding and use of genomic testing. Given that the UK model addresses, in the opinion of the stakeholders, many of these concerns, it is a natural model for policy makers to consider.

Acknowledgements Thank you to Gail Henderson, Debra Skinner, Mark Hall, Jean Cadigan, and Margaret Waltz for ongoing feedback. Thank you also to my advisory committee and research participants for input and participation. Thank you to my anonymous reviewers for comments that helped to improve this manuscript. Research reported here was supported by the National Human Genome Research Institute of the National Institutes of Health (Award K99R00HG008819).

\section{Compliance with ethical standards}

Conflict of interest The author declares that she has no conflict of interest.

Disclaimer The content is the responsibility of the author and does not represent the official views of the National Institutes of Health or those who provided feedback.

\section{References}

1. Wauters A, Van Hoyweghen I. Global trends on fears and concerns of genetic discrimination: a systematic literature review. J Hum Genet. 2016;61:275-82.

2. Joly Y, Feze IN, Song L, Knoppers BM. Comparative approaches to genetic discrimination: chasing shadows?'. Trends Genet. 2017;33:299-302. 
3. Lemmens T. Genetics and insurance discrimination: comparative legislative, regulatory and policy developments and Canadian option. Health Law J. 2003; 41-86.

4. Tarr JA. Regulatory approaches to genetic testing in insurance. Syd Law Rev. 2002;24:189.

5. Knoppers BM, Godard B, Joly Y. A comparative international overview. In: Rothstein MA, editor. Genetics and life insurance: medical underwriting and social policy; 2004. p. 173-94.

6. Joly Y, Braker M, Huynh ML. Genetic discrimination in private insurance: global perspective. N Genet Soc. 2010;29:351-68.

7. Concordat and Moratorium on Genetics and Insurance. London: HM Gov't \& Ass'n of British Insurers; 2011.

8. Code on Genetic Testing and Insurance", HM Gov't \& Ass'n of British Insurers; 2018.

9. The Genetic Non-discrimination Act, an Act to prohibit and prevent genetic discrimination; 2017. http://www.parl.ca/Document Viewer/en/42-1/bill/S-201/royal-assent.
10. Australian Law Reform Commission. Essentially yours-the protection of human genetic information in Australia. Canberra: ALRC; 2003.

11. Otlowski M, Barlow-Stewart K, Taylor S, Stranger M, Treloar S. Investigating genetic discrimination in the australian life insurance sector: the use of genetic test results in underwriting, 1999-2003. J Law Med. 2007;14:367-96.

12. Barlow-Stewart K, Liepins M, Doble A, Otlowski M. Abstract: How are genetic test results being used by Australian life insurers? Eur J Hum Genet 2018. 26:1248-1256 https://doi.org/10.1038/s41431018-0198-z.

13. Howard RCW. Genetic testing model: if underwriters had no access to known results. Ottowa: Canadian Institute of Actuaries; 2014.

14. Macdonald A, Yu F. The impact of genetic information on the insurance industry: conclusions from the 'Bottom-Up' Modelling Programme. Astin Bull. 2011;41:343-76. 